\title{
Enhanced All-Optical Y-Shaped Plasmonic OR, NOR And NAND Gate Models, Analyses, And Simulation For High Speed Computations
}

Ipshitha Charles

G. Pullaiah College of Engineering and Technology

Alluru Sreevani

G. Pullaiah College of Engineering and Technology

\section{SabbiVamshi Krishna}

Ravindra College of Engineering for Women

Sandip Swarnakar ( $\sim$ sandipswarnakar.2008@gmail.com)

G. Pullaiah College of Engineering and Technology https://orcid.org/0000-0003-3767-0916

\section{Santosh Kumar}

Liaocheng University

\section{Research Article}

Keywords: All-optical logic gate, MIM waveguide, plasmonic waveguide, Y-power combiner, finite-difference time-domain (FDTD)

Posted Date: December 30th, 2021

DOI: https://doi.org/10.21203/rs.3.rs-1054031/v1

License: (a) (i) This work is licensed under a Creative Commons Attribution 4.0 International License. Read Full License 


\section{Abstract}

In this digital era, all-optical logic gates (OLGs) proved its effectiveness in execution of high-speed computations. A unique construction of an all-optical OR, NOR, NAND gates based on the notion of power combiner employing metal-insulator-metal (MIM) waveguide in the Y-shape in a minimal imprint of 6.2 $\mu \mathrm{m} \times 3 \mu \mathrm{m}$ is presented and the structure is evaluated by finite-difference time-domain (FDTD) technique. The insertion loss (IL) and extinction-ratio (ER) for proposed model are $6 \mathrm{~dB}$ and $27.76 \mathrm{~dB}$ for NAND gate, 2 $\mathrm{dB}$ and $20.35 \mathrm{~dB}$ for NOR gate and $6 \mathrm{~dB}$ and $24.10 \mathrm{~dB}$ respectively. The simplified model is used in the construction of complex circuits to achieve greater efficiency, which contributes to the emergence of a new technique for designing plasmonic integrated circuits.

\section{Introduction}

The modern technology aims for rapid communication devices that can surpass the diffraction limit of photonic devices, and plasmonics have shown to be a viable option in this regard [1-3]. It is the science that focuses on generating, optical signal detecting and processing at metal-dielectric interface [4]. Plasmonic waveguides may be used to address the main disadvantages in a plasmonic circuit, such as restricted propagation time, rise in temperature and difficulty in changing the signal direction. In recent years, researchers have examined different plasmonic waveguides including MIM, IMI, and dielectricloaded surface plasmon polaritons (DLSPP) [5]. Compared to insulating waveguides, plasmonic MIM waveguides enable greater confinement and therefore been presented as a potential option for nanoscale optical circuits [6- 10]. Logic gates are essential components in all optical circuit design and a numerous optical equipments, like directional coupler (DC), Mach-Zehnder interferometer (MZI), power couplers, and power dividers, are utilized to realise logic gates such as AND, OR, NOT, XOR, and XNOR, along with universal gates such as NAND and NOR [11]. As a result, these all-OLGs may be utilised to construct any combinational circuit, including multiplexers, de-multiplexers, parity generator, adders and subtractors, and code translators [12-15]. Conventional OLGs give cut-off states and interferometric effects, but plasmonic logic gates greatly minimise size and signal losses; it can also lower signal thresholds of logic operations and offer rapid switching in optical devices.

The framework of the suggested paper presents a simplified all-optical NAND gate design with power coupling concept employing a Y-shaped waveguide and analysed using FDTD method. The Y-power coupler plasmonic NAND gate design is reported in Section 2. Section 3 presents the simulation findings. Section 4 has a results analysis, in which the current study is also compared to prior published studies, and Section 5 concludes the paper.

\section{The All-optical Plasmonic Nand Gate Structure Employing Y-power Combiner}

A miniaturized all-optical plasmonic NAND gate is modelled by arranging S-bend and linear waveguides of equal width (W) using power combiner concept. The presented design is obtained in a wafer size of $6.2 \mu \mathrm{m}$ 
$\times 3 \mu \mathrm{m}$ by arranging two parallel S-bend waveguides of equal length $\left(L_{s}\right)$ along $X Z$ axis in $Y$ shape separated by a distance (D) and joined to single end of a linear waveguide of length $(L)$ whose structure is shown in Fig.1. An external change in the phase controls the inputs supplied to both ends of the power combiner. The final minimised structure is achieved by varying the $Y$-combiner parameters such as the $L_{s}$ $D$, and $L$.

By altering the length of S-bend waveguide $\left(L_{S}\right)$ and maintaining the separation gap between inputs (D) as $2.5 \mu \mathrm{m}$, different factors like the highest output power when turned ON and OFF and also ER may be determined, as shown in Table 1. The output findings are used to determine performance metrics such as IL and ER.

$$
\text { Extinction ratio }(E R)=10 \log _{10}\left(\frac{P_{\text {out }} \mid \text { ON }}{P_{\text {out }} \mid \text { OFF }}\right)
$$

$\mathrm{P}_{\text {out }} \mid \mathrm{ON}$ and $\mathrm{P}_{\text {out }} \mid \mathrm{OFF}$ are power outputs in ON and OFF mode.

It is observed that for S-bend length of $3.6 \mu \mathrm{m}$, the obtained ER value is $27.76 \mathrm{~dB}$ that is higher compared to the rest. The S-bend length versus ER plot is depicted in Fig. 2.

Table 1 ER for different values of S-bend length $\left(L_{s}\right)$ in Y-shaped plasmonic NAND gate

\begin{tabular}{|lllll|}
\hline SI. No. & Length of S-bend waveguide $(\mu \mathrm{m})$ & $\mathrm{P}_{\mathrm{ON}}$ & $\mathrm{P}_{\mathrm{OFF}}$ & $\begin{array}{l}\text { Extinction ratio } \\
(\mathrm{dB})\end{array}$ \\
\hline 1 & 3.1 & 4.26 & 0.009 & 26.75 \\
\hline 2 & 3.2 & 4.31 & 0.008 & 27.31 \\
\hline 3 & 3.3 & 4.36 & 0.008 & 27.36 \\
\hline 4 & 3.4 & 4.37 & 0.008 & 27.37 \\
\hline 5 & 3.5 & 4.32 & 0.008 & 27.32 \\
\hline 6 & 3.6 & 4.18 & 0.007 & 27.76 \\
\hline 7 & 3.7 & 4.28 & 0.011 & 25.90 \\
\hline
\end{tabular}

Similarly, all parameters indicated are indeed computed by changing the value of $D$ by maintaining $L_{s}$ at $3.6 \mu \mathrm{m}$, the results are tabulated in Table 2. It is observed that ER is more for a separation between waveguide of $2.6 \mu \mathrm{m}$ resulting in $27.76 \mathrm{~dB}$. The separation between waveguides versus ER is plotted and displayed in Fig. 3.

Table 2 ER for various separations between S-bend waveguides (D) of the $Y$ shaped plasmonic NAND gate power combiner 


\begin{tabular}{|lllll|}
\hline SI. No. & D & $P_{\text {ON }}$ & P $_{\text {OFF }}$ & Extinction ratio (dB) \\
\hline 1 & 2.6 & 4.18 & 0.007 & 27.76 \\
\hline 2 & 2.7 & 4.40 & 0.01 & 26.43 \\
\hline 3 & 2.8 & 4.46 & 0.01 & 26.49 \\
\hline 4 & 2.9 & 4.46 & 0.01 & 26.49 \\
\hline 5 & 3.0 & 4.41 & 0.01 & 26.44 \\
\hline
\end{tabular}

The length of S-bend waveguide and D are maintained constant at $3.6 \mu \mathrm{m}$ and $2.6 \mu \mathrm{m}$, correspondingly, whereas the linear length of waveguide is adjusted to get the highest ER. Table 3 presents the ER for various linear lengths of waveguide. The higher $E R$ of $26.87 \mathrm{~dB}$ is reported for $L=2.5 \mu \mathrm{m}$. A linear length waveguide versus ER plot is depicted in Fig. 4 and the final dimensions of the Y-power coupler plasmonic NAND gate with the highest ER are tabulated in Table 3.

Table 3 ER of different linear waveguide lengths of Y-shaped plasmonic NAND gate

\begin{tabular}{|lllll|}
\hline SI. No. & Linear length & $\mathrm{P}_{\mathrm{ON}}$ & $\mathrm{P}_{\mathrm{OFF}}$ & $\begin{array}{l}\text { Extinction ratio } \\
\text { (dB) }\end{array}$ \\
\hline 1 & 2.4 & 4.32 & 0.009 & 26.81 \\
\hline 2 & 2.5 & 4.38 & 0.009 & 26.87 \\
\hline 3 & 2.6 & 4.36 & 0.009 & 26.85 \\
\hline 4 & 2.7 & 4.31 & 0.009 & 26.80 \\
\hline 5 & 2.8 & 4.29 & 0.009 & 26.78 \\
\hline 6 & 2.9 & 4.35 & 0.009 & 26.84 \\
\hline
\end{tabular}

From Table 1, 2, 3 it is observed that with $3.6 \mu \mathrm{m}, \mathrm{D}$ and as $2.6 \mu \mathrm{m}$ and $2.8 \mu \mathrm{m}$ has got the best ER. So, the footmark of the designed structure is fixed in the dimension of $6.2 \mu \mathrm{m} \times 3.0 \mu \mathrm{m}$. By considering the minimized structure's footmark the OR and NOR gates are also verified.

\section{The Y-power Combiner Plasmonic Gate Design And Fdtd Simulation Results}

The optimized all-optical OR, NOR, NAND gate design contains plasmonic waveguide of refractive index (n) $=2.1$ and continuous-waveform (CW) in transverse electric (TE) mode, with wavelength $(\lambda)$ of $1.55 \mu \mathrm{m}$ provided at both inputs. The power at input is $0.7 e^{9} \mathrm{~W} / \mathrm{m}$ and $3 e^{9} \mathrm{~W} / \mathrm{m}$ for low and high intensity optical signals, respectively. The presented structure is analysed using the FDTD technique and Table 4 shows the parameters of the simulation for the design proposed.

Table 4 The Y-shaped plasmonic OR, NOR, NAND gate power combiner Simulation parameters 


\begin{tabular}{|ll|}
\hline Simulation Parameters & Considered value \\
\hline Power at less intensity & $0.7 \times 10^{9} \mathrm{~W} / \mathrm{m}$ \\
\hline Power at high intensity & $3 \times 10^{9} \mathrm{~W} / \mathrm{m}$ \\
\hline Size of $X$ mesh $(\mu \mathrm{m})$ & 0.0114 \\
\hline Size of Z mesh $(\mu \mathrm{m})$ & 0.0114 \\
\hline X mesh cells & 349 \\
\hline Z mesh cells & 603 \\
\hline Transverse Input field & Gaussian \\
\hline
\end{tabular}

\section{1 OR gate}

Based on truth table of OR logic gate, when both inputs are low, the output is low; otherwise, it generates a high output. The explanation that follows gives details of different inputs and phase changes done to the Y-shape combiner to make it work with the OR outputs. In this instance, both the Y-combiner inputs are provided a signal of less- power intensity $0.7 \mathrm{e}^{9} \mathrm{~W} / \mathrm{m}$. According to the OR gate truth table, the output power is noted to be low. varied phase of $180^{\circ}$ and $0^{\circ}$ is given to both input signals resulting in destructive interference and the OR gate output is observed to be low $(Y=0)$ as shown in Fig. 5(a). For next case, the upper end of combiner is given less- power intensity $\left(0.7 \mathrm{e}^{9} \mathrm{~W} / \mathrm{m}\right)$ in contrast the lower end of combiner is provided a signal of greater-power intensity $\left(3 \mathrm{e}^{9} \mathrm{~W} / \mathrm{m}\right)$. A same phase of $180^{\circ}$ or $0^{\circ}$ is allowed in both inputs resulting in constructive interference thereby the OR gate's output is high $(Y=1)$, as illustrated in Fig. 5 (b). In contrast to the preceding instance, the upper end of combiner is given a greater intensity $\left(3 e^{9} \mathrm{~W} / \mathrm{m}\right)$ whereas the below end is provided a signal of less-intensity power $\left(0.7 e^{9} \mathrm{~W} / \mathrm{m}\right)$. Due to constructive interference, high output of OR gate $(Y=1)$ is achieved as depicted in Fig. 5(c). Finally, the two inputs of power coupler are provided a high intensity power signal $\left(3 \mathrm{e}^{9} \mathrm{~W} / \mathrm{m}\right)$, same phase of $180^{\circ}$ or $0^{\circ}$ is provided resulting in constructive interference with high output $(Y=1)$ as shown in Fig. $5(d)$.

\subsection{NOR Logic Gate}

According to the truth table of NOR logic gate, when both inputs are low, the NOR logic gate creates a high output; but provides low output for the rest. The explanation that follows goes into detail into the various inputs and phase shifts used by the Y-shape combiner to meet the NOR output's requirements. In the first instance, both the Y-combiner inputs are provided a signal of less- power intensity $0.7 e^{9} \mathrm{~W} / \mathrm{m}$. Same phase of $180^{\circ}$ or $0^{\circ}$ is given to both input signals resulting in constructive interference and the NOR gate output is observed to be higher $(Y=1)$ as shown in Fig. 6(a). in the next case, upper end of combiner is given lesspower intensity $\left(0.7 \mathrm{e}^{9} \mathrm{~W} / \mathrm{m}\right)$ in contrast the lower end of combiner is provided a signal of greater-power intensity $\left(3 e^{9} \mathrm{~W} / \mathrm{m}\right)$. As in the preceding example, destructive interference will arise, reducing the strength of the output signal. As a result, the NOR gate's output is low $(Y=0)$, as illustrated in Fig. 6(b). In contrast 
to the preceding case, the upper end of combiner is given a greater intensity $\left(3 e^{9} \mathrm{~W} / \mathrm{m}\right)$ whereas the below end is provided a signal of less-intensity power $\left(0.7 \mathrm{e}^{9} \mathrm{~W} / \mathrm{m}\right)$. Due to destructive interference, resulting in low output of NOR gate $(\mathrm{Y}=0)$ as depicted in Fig. 6(c). Finally, the two inputs of power coupler are provided a high intensity power signal $\left(3 e^{9} \mathrm{~W} / \mathrm{m}\right)$, The phase for one input is $180^{\circ}$ and the other is $0^{\circ}$ resulting in destructive interference resulting in low output intensity $(Y=0)$ as shown in Fig. 6(d).

\subsection{NAND Logic Gate}

When both inputs are high in a NAND logic gate, the output is low; otherwise, the output is high. An explanation of how the NAND output alters with phase in a Y-shape combiner can be found below. Figure 7 depicts the propagation of light along the proposed NAND gate for the specified input signal pairings using the FDTD method. In the initial state, both the Y-combiner inputs are provided a signal of less- power intensity $0.7 \mathrm{e}^{9} \mathrm{~W} / \mathrm{m}$. According to the NAND gate truth table, the output power is noted to be high. Same phase of $180^{\circ}$ or $0^{\circ}$ is given to both input signals resulting in constructive interference and the NAND gate output is observed to be higher $(Y=1)$ as shown in Fig. 7(a). While in the next case, the upper end of combiner is given less-power intensity $\left(0.7 \mathrm{e}^{9} \mathrm{~W} / \mathrm{m}\right)$ and in contrast the lower end of combiner is provided a signal of greater-power intensity $\left(3 \mathrm{e}^{9} \mathrm{~W} / \mathrm{m}\right)$. A same phase of $180^{\circ}$ or $0^{\circ}$ is allowed in both inputs. As in the preceding example, destructive interference will arise, reducing the strength of the output signal. As a result, the NAND gate's output is high $(Y=1)$, as illustrated in Fig. 7(b). In contrast to the preceding instance, the upper end of combiner is given a greater intensity $\left(3 e^{9} \mathrm{~W} / \mathrm{m}\right)$ whereas the below end is provided a signal of less-intensity power $\left(0.7 e^{9} \mathrm{~W} / \mathrm{m}\right)$. Thereby, due to the same phase, constructive interference will arise, resulting in high output of NAND gate $(Y=1)$ as depicted in Fig. 7(c). Finally, the two inputs of power coupler are provided a high intensity power signal $\left(3 e^{9} \mathrm{~W} / \mathrm{m}\right)$ The phase for one input is $180^{\circ}$ and the other is $0^{\circ}$ resulting in destructive interference resulting in low output intensity $(Y=0)$ as shown in Fig. 7(d).

\section{Performance Analysis}

The suggested device has a $6.2 \mu \mathrm{m} \times 3 \mu \mathrm{m}$ footprint. So, the proposed design obtained IL and ER of $6 \mathrm{~dB}$ and $27.76 \mathrm{~dB}$. The other parameters like response time of $32 \mathrm{fs}$ and bit rate of $31.25 \mathrm{THz}$ is observed. A comparison of the proposed structure with previous published works is made and tabulated in Table 5. 
Table 5

Comparison of the suggested all-optical Y shaped plasmonic NAND gate with the previously proposed design performance

\begin{tabular}{|c|c|c|c|c|c|c|c|c|}
\hline $\begin{array}{l}\text { SI. } \\
\text { No. }\end{array}$ & $\begin{array}{l}\text { Ref. } \\
\text { No. }\end{array}$ & $\begin{array}{l}\text { Material } \\
\text { used }\end{array}$ & $\begin{array}{l}\text { Extinction } \\
\text { ratio (dB) }\end{array}$ & Footprint & $\begin{array}{l}\text { Refractive } \\
\text { index }\end{array}$ & $\begin{array}{l}\text { Low } \\
\text { intensity }\end{array}$ & $\begin{array}{l}\text { High } \\
\text { intensity }\end{array}$ & Structure \\
\hline 1 & [16] & $\begin{array}{l}\text { PhC } \\
\text { waveguide }\end{array}$ & 14.2 & $192 \mu \mathrm{m}^{2}$ & $\mathrm{n} \cdot \mathrm{r}^{\mathrm{a}}$ & $\mathrm{n} \cdot \mathrm{r}^{\mathrm{a}}$ & $n \cdot r^{a}$ & 2D PhC \\
\hline 2 & [17] & $\begin{array}{l}\text { MIM } \\
\text { waveguide }\end{array}$ & 10.25 & $\begin{array}{l}40 \times 7.5 \\
\mu \mathrm{m}^{2}\end{array}$ & 2.01 & $\begin{array}{l}0.7 e^{9} \\
W / m\end{array}$ & $\begin{array}{l}3 e^{9} \\
W / m\end{array}$ & $\begin{array}{l}\text { Plasmonic } \\
\text { MZI }\end{array}$ \\
\hline 3 & [18] & $\begin{array}{l}\text { Plasmonic } \\
\text { MIM } \\
\text { waveguide }\end{array}$ & 14.11 & $\begin{array}{l}7 \times 4 \\
\mu \mathrm{m}^{2}\end{array}$ & 2.1 & $\begin{array}{l}2 e^{9} \\
W / m\end{array}$ & $\begin{array}{l}3 e^{9} \\
W / m\end{array}$ & $\begin{array}{l}\text { Y shaped } \\
\text { power } \\
\text { combiner }\end{array}$ \\
\hline 4 & [19] & $\begin{array}{l}\text { Plasmonic } \\
\text { MIM } \\
\text { waveguide }\end{array}$ & 10.55 & $\begin{array}{l}36 \times 8 \\
\mu m^{2}\end{array}$ & 2.01 & $\begin{array}{l}0.7 e^{9} \\
W / m\end{array}$ & $\begin{array}{l}3 e^{9} \\
W / m\end{array}$ & $\begin{array}{l}\text { two } \\
\text { nonlinear } \\
\text { MZI }\end{array}$ \\
\hline 5 & [20] & $\begin{array}{l}\text { Plasmonic } \\
\text { IMI } \\
\text { waveguide }\end{array}$ & 20 & $\begin{array}{l}400 \mathrm{~nm} \\
\times 380 \\
\mathrm{~nm}\end{array}$ & 1.375 & n. r $^{a}$ & n. r $^{a}$ & $\begin{array}{l}\text { four } \\
\text { nanorings } \\
\text { resonators } \\
\text { and three } \\
\text { straight } \\
\text { stripes }\end{array}$ \\
\hline 6 & [21] & $\begin{array}{l}\text { Plasmonic } \\
\text { MIM } \\
\text { waveguide }\end{array}$ & $25 \mathrm{~dB}$ & $\begin{array}{l}5 \mathrm{~nm} \times 5 \\
\mathrm{~nm}\end{array}$ & 1 & $\mathrm{n} \cdot \mathrm{r}^{\mathrm{a}}$ & n. $r^{a}$ & $\begin{array}{l}\text { nanoslot } \\
\text { cavity } \\
\text { resonators }\end{array}$ \\
\hline 7 & $\begin{array}{l}\text { This } \\
\text { work }\end{array}$ & $\begin{array}{l}\text { Plasmonic } \\
\text { MIM } \\
\text { waveguide }\end{array}$ & 27.76 & $\begin{array}{l}6.2 \times 3 \\
\mu \mathrm{m}^{2}\end{array}$ & 2.1 & $\begin{array}{l}0.7 e^{9} \\
W / m\end{array}$ & $\begin{array}{l}3 e^{9} \\
W / m\end{array}$ & $\begin{array}{l}\text { Y shaped } \\
\text { power } \\
\text { combiner }\end{array}$ \\
\hline
\end{tabular}

\section{Conclusion}

The suggested Y-shaped MIM waveguide concept is utilised to construct an all-optical OR, NOR, NAND logic gate. The structure has a surface area of $6.2 \mu \mathrm{m} \times 3 \mu \mathrm{m}$, which is less than earlier efforts. In this study, the IL and ER calculated are key factors that are determined to be $6 \mathrm{~dB}$ and $27.76 \mathrm{~dB}$, respectively and response time of $32 \mathrm{fs}$ and bit rate of $31.25 \mathrm{THz}$ are also observed. The length of S-bend waveguide, input separation, and linear length of waveguide are designed to provide the highest ER while minimising waveguide losses. The Y-combiner-based NAND gate, with its simple construction and controllability, can provide a novel approach for implementing digital logic functions in electronics. The presented design has a simplified structure that might be utilized to develop ultra-compact devices for rapid optical computing in the future.

\section{Declarations}


Acknowledgment

This work was supported by the Science and Engineering Research Board, India [grant number:

TAR/2018/000051].

\section{Availability of data and material}

The authors can provide the data on request.

\section{Code availability}

No source code is available for this manuscript.

\section{Declarations}

The authors declare that they have no conflict of interest.

\section{Consent to participate}

For this type of study formal consent is not required.

\section{References}

1. Pal, A., Ahmed, M.Z., Swarnakar, S.: An optimized design of all-optical XOR, OR, and NOT gates using plasmonic waveguide. Opt. Quant. Electron. 53(2), 1-13 (2021)

2. Cotter, D., Manning, R.J., Blow, K.J., Ellis, A.D., Kelly, A.E., Nesset, D., Phillips, I.D., Poustie, A.J., Rogers, D.C.: Nonlinear optics for high-speed digital information processing. Sci. 286(54444), 1523-1528 (1999)

3. Rezaei, M.H., Zarifkar, A., Miri, M.: Ultra-compact electro-optical graphene-based plasmonic multi-logic gate with high extinction ratio. Opt. Mat. 84, 572-578 (2018)

4. Sorger, V.J., Oulton, R.F., Ma, R.M., Zhang, X.: Toward integrated plasmonic circuits. MRS bulletin. 37(8), 728-738 (2012). https://doi.org/10.1557/mrs.2012.170

5. Moradi, M., Danaie, M., Orouji, A.A.: Design of all-optical XOR and XNOR logic gates based on Fano resonance in plasmonic ring resonators. Opt. Quant. Electron. 51(5), 1-18 (2019)

6. Chen, Z., Holmgaard, T., Bozhevolnyi, S.I., Krasavin, A.V., Zayats, A.V., Markey, L., Dereux, A.: Wavelength-selective directional coupling with dielectric-loaded plasmonic waveguides. Opt. Lett. 34(3), 310-312 (2009)

7. Singh, L., Bedi, A., Kumar, S.: Modeling of all-optical $3 \times 8$ line decoder using optical Kerr effect in plasmonic metal-insulator-metal waveguides. Proc. SPIE Opto. 10109, 1-7 (2017). https://doi.org/10.1117/12.2249660

8. Dolatabady, A., Granpayeh, N.: All optical logic gates based on two dimensional plasmonic waveguides with nanodisk resonators. J. Opt. Soc. Korea. 16(4), 432-442 (2012) 
9. Sadeghi, T., Golmohammadi, S., Farmani, A., Baghban, H.: Improving the performance of nanostructure multifunctional graphene plasmonic logic gates utilizing coupled-mode theory. Appl. Phys. B. 125(10), 1-12 (2019)

10. Sharma, S., Zafar, R., Mahdieh, M.H., Singh, G., Salim, M.: High Contrast Ratio Based All-Optical OR and NOR Plasmonic Logic Gate Operating at E Band. Opt. Wireless Tech. 546, 325332 (2020). https://doi.org/10.1007/978-981-13-6159-3_35

11. Rao, D.G.S., Palacharla, V., Swarnakar, S., Kumar, S.: Design of all-optical D flip-flop using photonic crystal waveguides for optical computing and networking. Appl. Opt. 59(23), 7139-7143 (2020)

12. Meymand, R. E., Soleymani, A., Granpayeh, N.: All-optical AND, OR, and XOR logic gates based on coherent perfect absorption in graphene-based metasurface at terahertz region. Opt. Commun. 458, 113 (2020). https://doi.org/10.1016/j.optcom.2019.124772

13. Kumar, S., Singh, L., Swarnakar, S.: Design of one-bit magnitude comparator using nonlinear plasmonic waveguide. Plasmon. 12(2), 369-375 (2017)

14. Swarnakar, S., Rathi, S., Kumar, S.: Design of all optical XOR gate based on photonic crystal ring resonator. J. Opt. Commun. 41(1), 51-56 (2020)

15. Rao, D.G.S., Swarnakar, S., Palacharla, V., Raju, K.S.R., Kumar, S.: Design of all-optical AND, OR, and XOR logic gates using photonic crystals for switching applications. Photon. Netw. Commun. 41(1), 109-118 (2021). https://doi.org/10.1007/s11107-020-00916-6

16. Safinezhad, A., Ghoushji, H.B., Shiri, M. and Rezaei, M.H.: High-performance and ultrafast configurable all-optical photonic crystal logic gates based on interference effects. Opt. Quant. Electron. 53(5), 1-20 (2021)

17. Singh, A., Pal, A., Singh, Y. and Sharma, S.: Design of optimized all-optical NAND gate using metalinsulator-metal waveguide. Opt. 182, 524-528 (2019)

18. Anguluri, S.P.K., Banda, S.R., Krishna, S.V., Swarnakar, S., Kumar, S.: Design, Analysis, and Simulation of All-optical Optimized and Gate using Y-shaped Plasmonic Waveguide for High-speed Computing Devices. J. Comput. Electron. 44, 1-8 (2021). https://doi.org/10.21203/rs.3.rs-327354/v1

19. Swarnakar, S., Reddy, S.K., Harijan, R., Kumar, S.: Design and modelling of all-optical NAND gate using metal-insulator-metal (MIM) waveguides based Mach-Zehnder Interferometers for high-speed information processing. Opt. Quant. Electron. 53(9), 1-13 (2021)

20. Al-Musawi, H.K., Al-Janabi, A.K., Al-abassi, S.A., Abusiba, N.A.H.A., Al-Fatlawi, N.A.H.Q.: Plasmonic logic gates based on dielectric-metal-dielectric design with two optical communication bands. Opt. 223, 1$14(2020)$

21. Dolatabady, A. and Granpayeh, N.: All-optical logic gates in plasmonic metal-insulator-metal nanowaveguide with slot cavity resonator. J. Nanophoton. 11(2), 1-8 (2017)

\section{Figures}




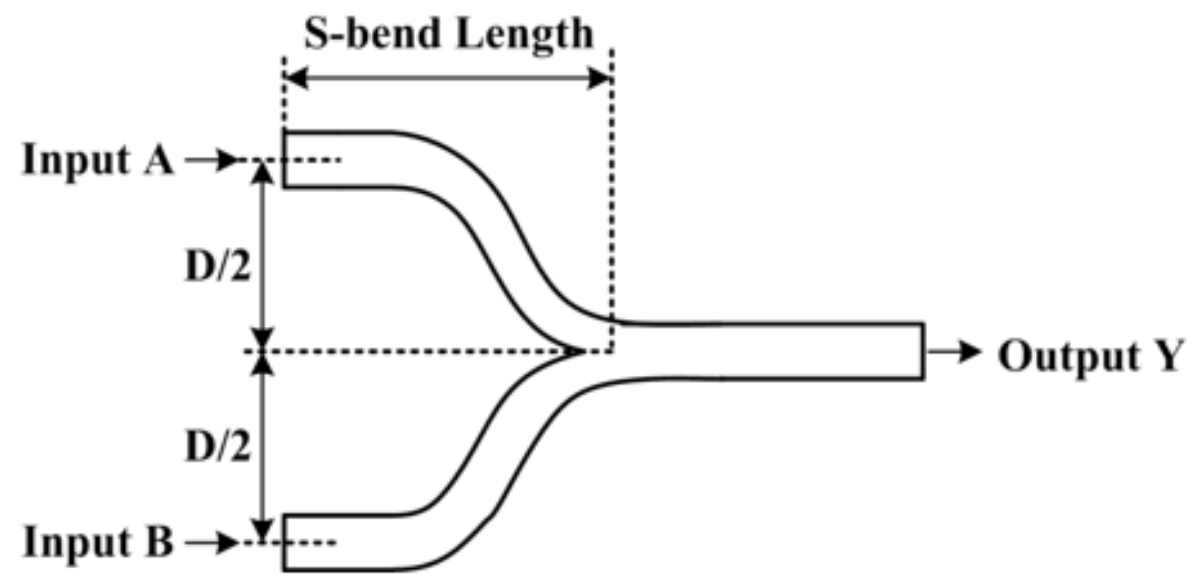

Figure 1

Schematic of $Y$ shaped NAND logic gate using plasmonic waveguide

Figure 2

S-bend length versus ER plot at $D=2.5 \mu \mathrm{m}$

Figure 3

Separation between input waveguides (D) versus ER plot with $L_{s}=2.5 \mu \mathrm{m}$ 


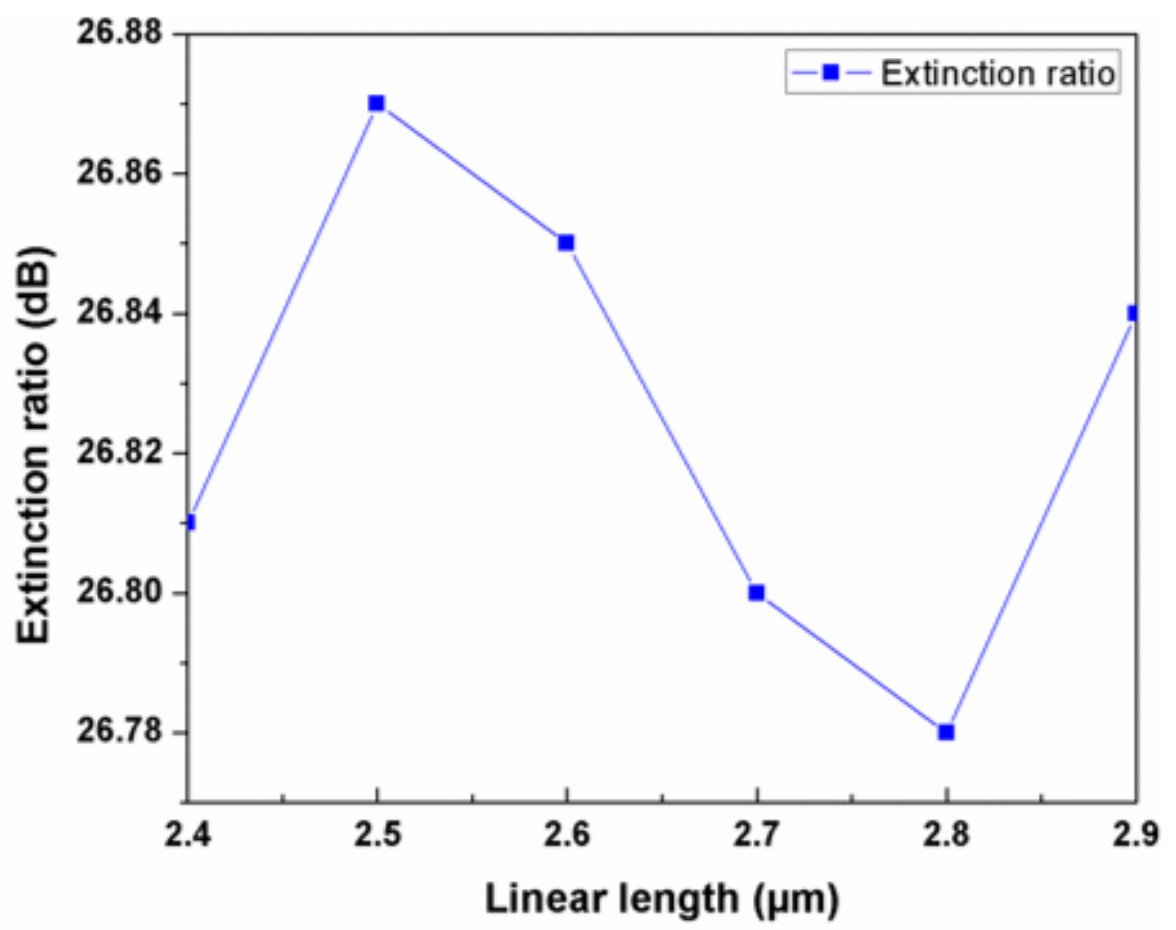

Figure 4

Linear length versus ER plot at $L_{s}=3.6 \mu \mathrm{m}$ and $D=2.6 \mu \mathrm{m}$ 

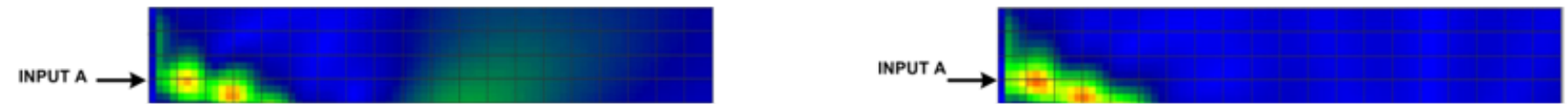

\section{Figure 5}

Propagation of light across the suggested $Y$ shaped plasmonic OR gate power combiner for various instances using FDTD method
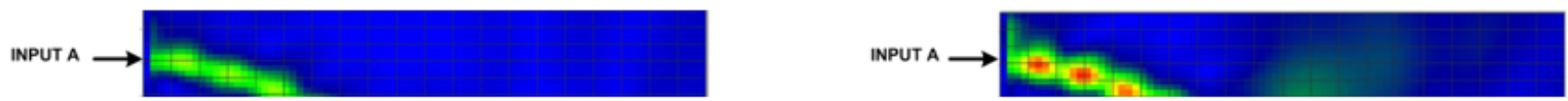

Figure 6 
Propagation of light across the suggested $Y$ shaped plasmonic NOR gate power combiner for various instances using FDTD method

\section{Figure 7}

Propagation of light across the suggested $Y$ shaped plasmonic NAND gate power combiner for various instances using FDTD method 